\title{
Analisis Kebutuhan Sarana Penghubung Kampus Universitas Negeri Surabaya Berdasarkan Persepsi Pengguna (Tenaga Pendidik Dan Mahasiswa)
}

\author{
Fitri Rohmah Widayanti ${ }^{1}$, Purwo Mahardi ${ }^{1}$ \\ ${ }^{1}$ Jurusan Teknik Sipil, Fakultas Teknik, Universitas Negeri Surabaya, Jln. Ketintang Surabaya. Telp: (031) 1234567. \\ Email : fitrirohmah_214@yahoo.com
}

\begin{abstract}
Abstrak
Pengelolaan transportasi secara cepat dan akurat, tentu saja tidak terlepas dari peningkatan aspek kualitas pelayanan.Kondisi ini diharapkan terjadi pada transportasi mahasiswa di perguruan tinggi, terutama yang berkaitan dengan pelayanan jasa transportasi bus kampus di perguruan tinggi bersangkutan. Universitas Negeri Surabaya belum memiliki fasilitas layanan bus kampus. Hasil kuesioner menunjukkan prosentase terbesar adalah sangat berminat yaitu 62\% untuk mahasiswa dan 64\% untuk tendik. Hal ini menunjukkan bahwa apabila bus kampus nantinya akan direalisasikan, minat dari warga Unesa terhadap layanan kampus tersebut cukup tinggi.
\end{abstract}

Kata Kunci: Bus kampus, kuesioner, transportasi.

\section{Abstract}

Transportation management is fast and accurate, of course, not apart from the improvement of service quality aspect.This condition is expected to occur in the transportation of students in universities, especially those related to campus bus transportation services in the college concerned. Surabaya State University does not have campus bus service facilities. The results of the questionnaire showed the greatest percentage is very interested that is $62 \%$ for students and $64 \%$ for the tendik. This indicates that if the campus bus will be realized, the interest of Unesa residents to the campus service is quite high.

Keywords: Campus bus, questionnaire, transportation.

\section{LATAR BELAKANG}

Kemudahan akses suatu wilayah dapat ditinjau dari tersedianya sarana transportasi yang melayani wilayah tersebut. Kemudahan akses tersebut tentu tidak lepas dari penyediaan pelayanan transportasi yang baik. Penyediaan jasa transportasi yang baik sangat diperlukan oleh pihak penyelenggara, dalam hal ini pihak penyelenggara adalah pihak kampus. Kebutuhan pergerakan di kampus Lidah Wetan Universitas Negeri Surabaya ditunjukkan pada Tabel 1 yang menjadi alasan perlunya direncanakan suatu transportasi kampus yang melayani pergerakan aktifitas di kawasan dalam kampus.

Tabel 1 Kebutuhan pergerakan dalam kampus

\begin{tabular}{ccc}
\hline Objek & $\begin{array}{c}\text { Kebutuhan } \\
\text { Pergerakan }\end{array}$ & \multicolumn{1}{c}{ Bentuk Pergerakan } \\
\hline \multirow{3}{*}{ Dosen } & $\begin{array}{c}\text { Akademik } \\
\text { (prodi/antar } \\
\text { prodi) \& non } \\
\text { akademik }\end{array}$ & - Masuk \& keluar kampus \\
& Urusan & - Antar Prodi \& antar kluster \\
\hline \multirow{2}{*}{ Karyawan } & administrasi & - Antar prodi/fakultas/ unit \\
& Kuliah & - Eksternal (gedung pusat) \\
\hline \multirow{2}{*}{ Mahasiswa } & - Kuliah di prodi \& kluster lain \\
\hline
\end{tabular}

Bus kampus merupakan salah satu sarana transportasi yang telah banyak digunakan di beberapa universitas di Indonesia. Bus kampus dianggap lebih efektif dan efisien karena dapat mengakut penumpang dengan jumlah yang banyak. Penggunaan bus kampus diharapkan dapat menjadi sarana yang tepat guna menunjang kemudahan akses untuk segala aktifitas di dalam kawasan kampus Unesa Lidah Wetan.

\section{METODOLOGI}

Penelitian ini menggunakan pendekatan deskriptif kualitatif, karena permasalahan yang dibahas dalam penelitian ini tidak berhubungan dengan angka, tetapi berkaitan dengan pendeskripsian, penguraian dan penggambaran suatu masalah yang sedang terjadi. Jenis penelitian ini termasuk penelitian yang rinci mengenai suatu subyek tertentu selama kurun waktu tertentu dengan cukup waktu mendalam 
dan menyeluruh termasuk lingkungan dan kondisi masa depan.

Langkah awal dari penelitian ini adalah pengumpulan data yaitu data primer. Data primer yaitu data hasil penyebaran kuesioner dengan responden adalah tendik dan mahasiswa di kampus Unesa Lidah Wetan. Dari data yang sudah dikumpulkan dianalisa bagaimana deskripsi pelayanan buus kampus yang diingikan oleh responden.

Analisa yang dilakukan akan menghasilkan bentuk pelayanan bus kampus guna menunjang gerakan eco campus Unesa. Sistematika penyelesaian masalah berdasarkan teori yang ada disusun sebagai berikut.

\section{Moda transportasi}

Secara umum, ada 2 (dua) kelompok besar moda transportasi, dalam hal ini yang dimaksudkan adalah moda angkutan umum yaitu:

1)

(private transportation), yaitu moda transportasi yang dikhususkan buat pribadi seseorang dan seseorang itu bebas memakainya ke mana saja, di mana saja dan kapan saja dia mau, bahkan mungkin juga tidak memakainya sama sekali (disimpan di garasi).

2)

(public transportation), yaitu moda transportasi yang diper untukan buat bersama (orang banyak), kepentingan bersama, menerima pelayanan bersama, mempunyai arah dan titik tujuan yang sama, serta terikat de ngan peraturan trayek yang sudah ditentukan dan jadwal yang sudah ditetapkan dan para pelaku perjalanan harus menyesuaikan diri dengan ketentuanketentuan tersebut apabila angkutan umum ini sudah mereka pilih (Miro, 2005:116). Sedangkan menurut Warpani (1990: 170) angkutan umum penumpang adalah angkutan penumpang yang dilakukan dengan sistem sewa atau bayar. Yang termasuk dalam angkutan umum penumpang adalah angkutan kota (bus, minibus, dsb), kereta api, angkutan air dan udara.

\section{Metode Analisis Deskriptif}

Metode deskriptif adalah penelitian yang dilakukan untuk mengetahui keberadaan variabel mandiri, baik hanya pada satu variabel atau lebih (variabel yang berdiri sendiri) tanpa membuat perbandingan dan mencari hubungan variabel itu dengan variabel yang lain". Sugiyono (2009:35)

Dari pengertian di atas dapat disimpulkan bahwa metode deskriptif analisis dengan pendekatan kuantitatif merupakan metode yang bertujuan menggambarkan secara sistematis dan faktual tentang fakta-fakta serta hubungan antar variabel yang diselidiki dengan cara mengumpulkan data, mengolah, menganalisis, dan menginterpretasi data dalam pengujian hipotesis statistik.

Prosedur yang digunakan dalam penelitian digambarkan dalam diagram alir berikut.

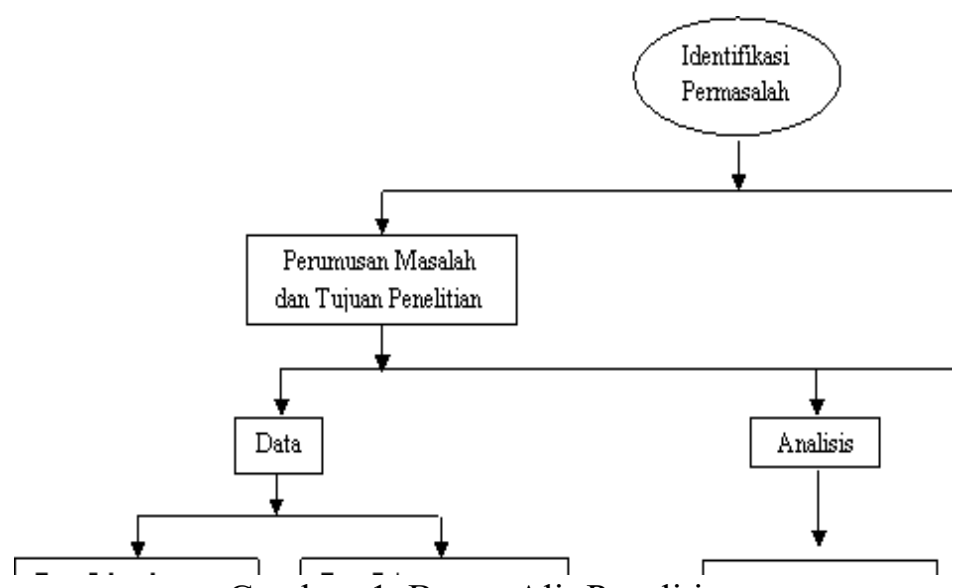

Gambar 1. Bagan Alir Penelitian

\section{HASIL DAN PEMBAHASAN}

Penelitian ini bertujuan untuk mengkaji pengadaan bus kampus dengan pokok-pokok kajian penelitian yaitu rute yang akan dilalui bus kampus, jadwal pengoperasian bus kampus, letak halte bus kampus, serta atribut pelayanan bus kampus.

Pengadaan bus kampus selain sebagai sarana pelayanan transportasi diharapkan juga dapat mendukung gerakan eco campus (green campus). Berdasarkan hasil kuesioner diketahui minat responden untuk berpindah ditunjukkan pada Gambar 2 dan Gambar 3.

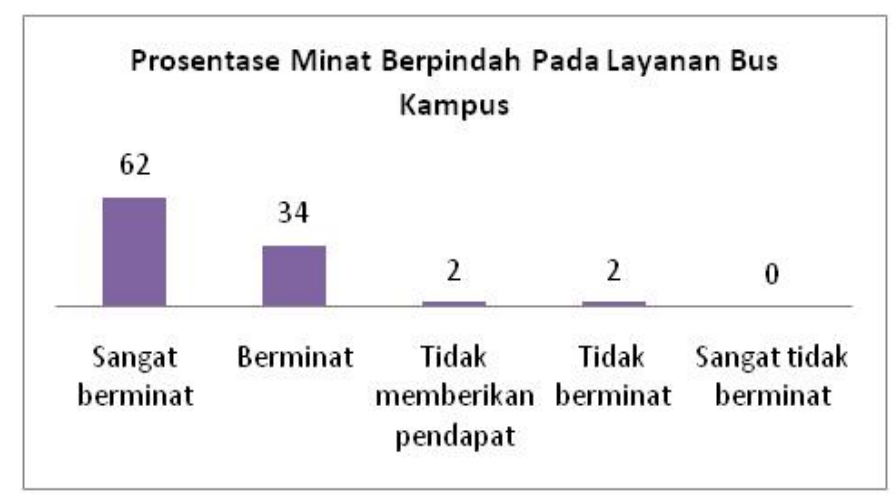


Gambar 2. Grafik Prosentase Minat Berpindah

Responden Mahasiswa

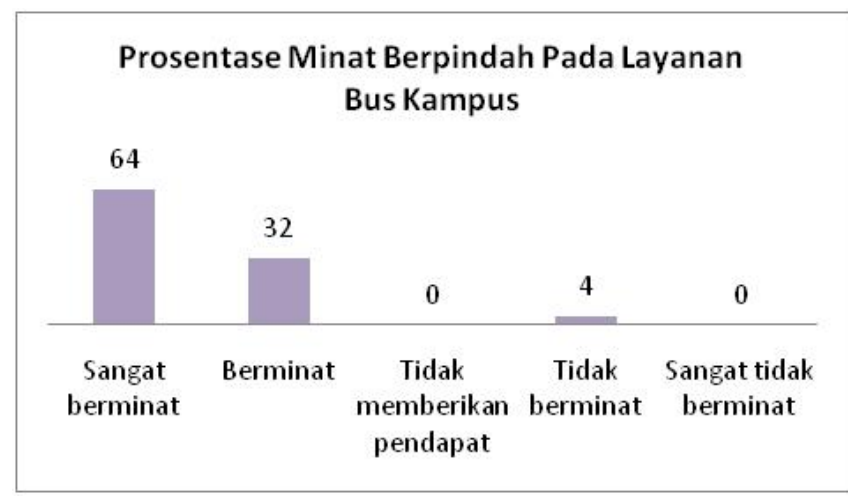

Gambar 3. Grafik Prosentase Minat Berpindah Dengan Responden Tenaga Pendidik

Berdasarkan Gambar 2 dan Gambar 3, diketahui bahwa baik responden mahasiswa atau tenaga tendik (tendik) jawaban prosentase terbesar adalah sangat berminat yaitu $62 \%$ untuk mahasiswa dan $64 \%$ untuk tendik. Hal ini menunjukkan bahwa apabila bus kampus nantinya akan direalisasikan, minat dari warga Unesa terhadap layanan kampus tersebut cukup tinggi.

Rencana jadwal operasi bus kampus berdasarkan persepsi responden dilihat dari hasil kuesioner dari waktu memasuki kawasan kampus dan waktu meninggalkan kampus yang dapat dilihat pada Gambar 4, Gambar 5, Gambar 6, dan Gambar 7.

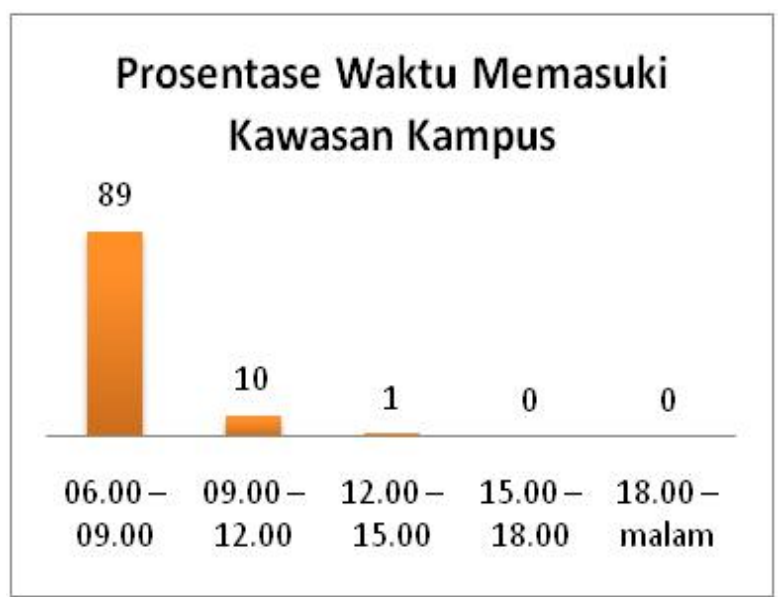

Gambar 4. Grafik Prosentase Waktu Memasuki Kampus Dengan Responden Mahasiswa

\section{Prosentase Waktu Memasuki Kawasan Kampus}

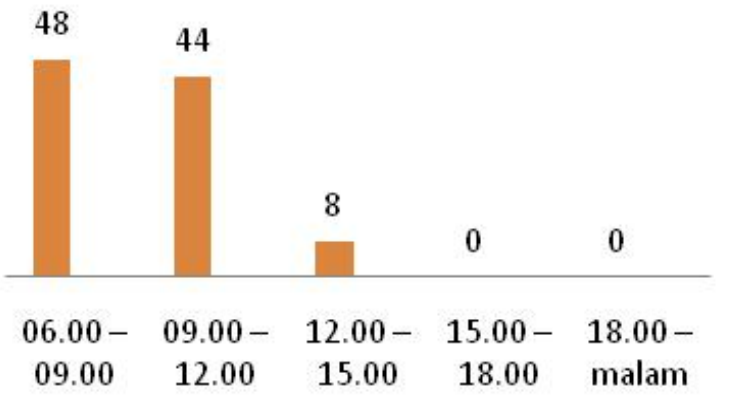

Gambar 5. Grafik Prosentase Waktu Memasuki Kampus Dengan Responden Tendik

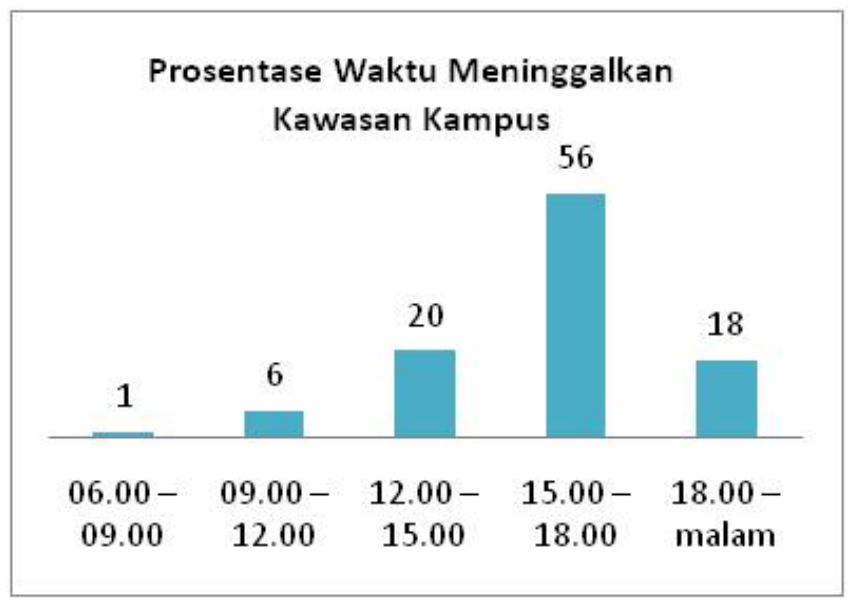

Gambar 6. Grafik Prosentase Waktu Meninggalkan Kampus Dengan Responden Mahasiswa

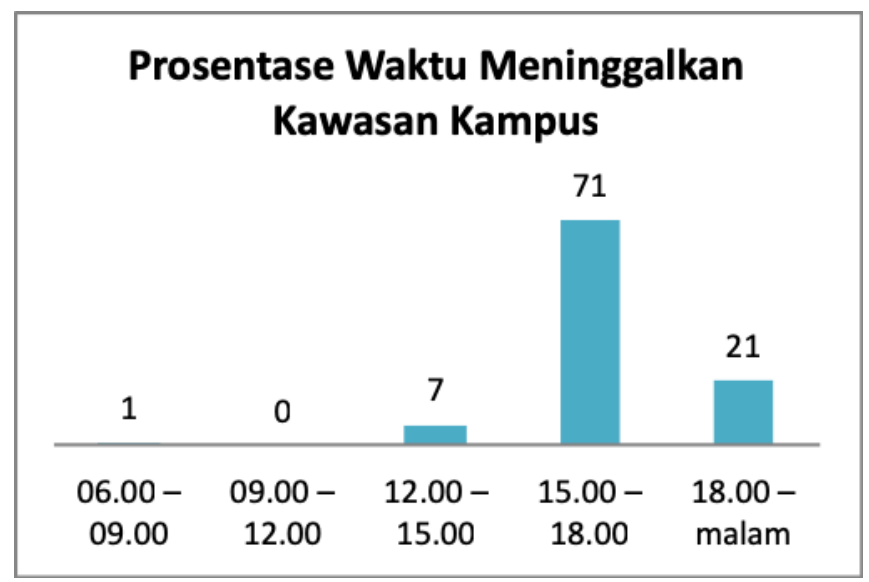


Gambar 7. Grafik Prosentase Waktu Meninggalkan Kampus Dengan Responden Tendik

Berdasarkan hasil kuesioner, untuk waktu operasional bus kampus pagi adalah pukul 06.00-09.00 WIB, sedangkan waktu operasional bus kampus sore adalah pukul 15.00-18.00 WIB.

Rute bus kampus akan direncanakan berdasarkan prosentase terbesar dari pilihan rute yang diberikan di dalam kuesioner, hasil dari kuesioner dapat dilihat pada Gambar 8 dan Gambar 9

\section{Prosentase Rute Yang Di Minati Untuk Bus Kampus}

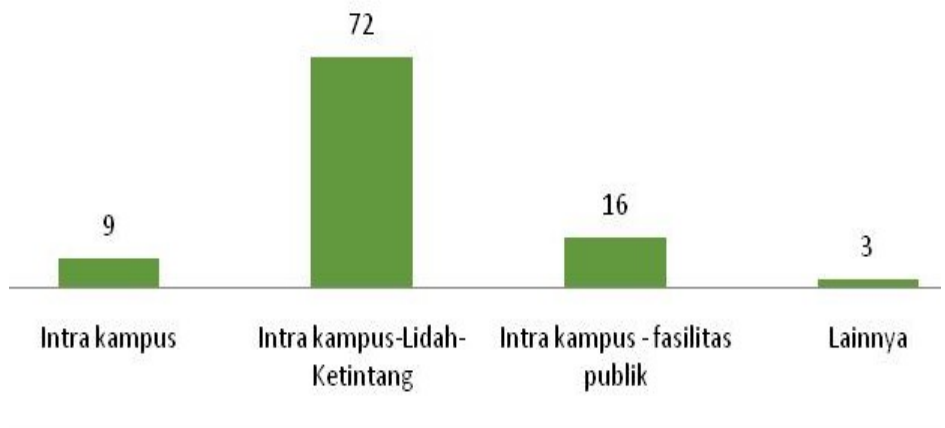

Gambar 8. Grafik Prosentase Rute yang Diminati Responden Tendik

Prosentase Rute Yang Di Minati Untuk Bus Kampus

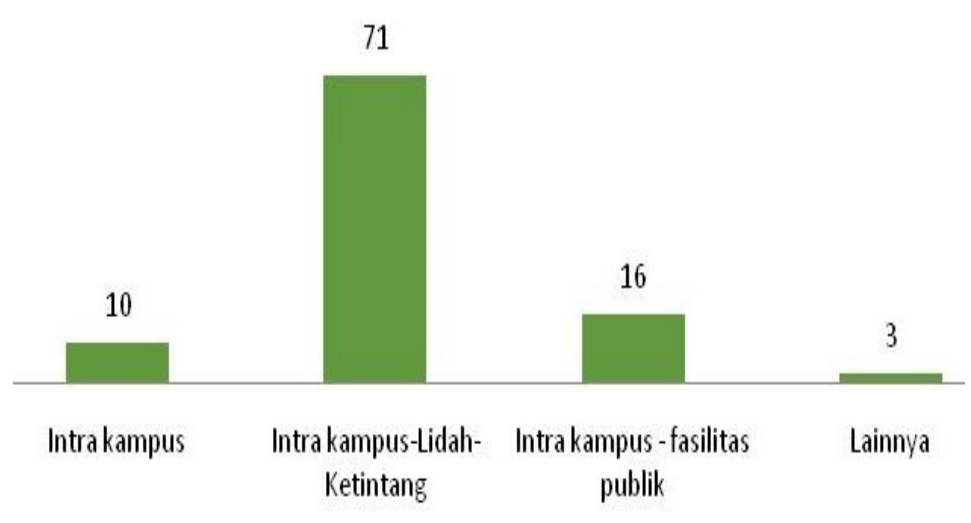

Gambar 9. Grafik Prosentase Rute yang

Diminati Responden Mahasiswa

Berdasarkan Gambar 8 dan Gambar 9, rute yang sebenarnya paling diminati adalah rute Kampus Lidah Wetan menuju Kampus Ketintang. Namun sebagai permulaan, penulis mengusulkan rute pembuka yang hanya akan mengakomodasi minat perjalanan di Kawasan intra kampus Lidah Wetan.

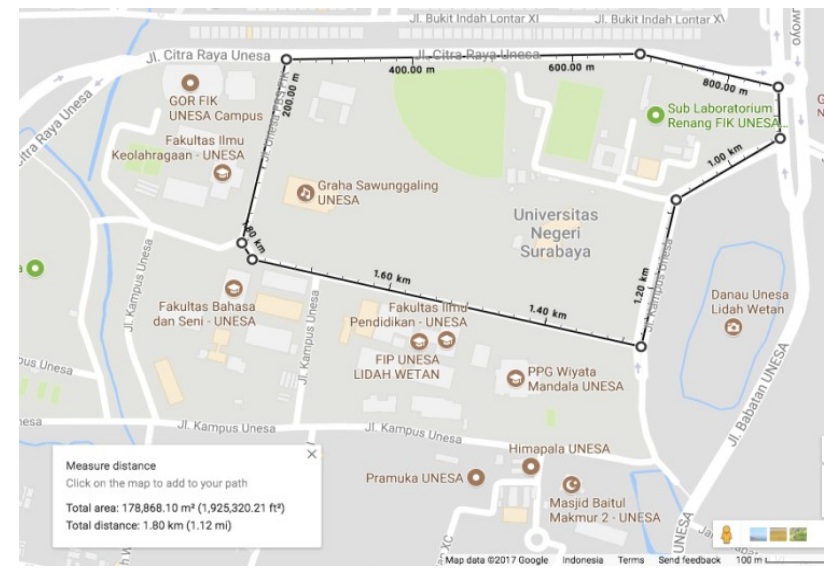

Gambar 10. Usulan Rencana Rute Permulaan

Konsep pengembangan rute menjadi Kampus Lidah Wetan - Kampus Ketintang, akan dilakukan dengan melihat kecenderungan minat pada rute pioneer yakni intra kampus Lidah Wetan.

Halte bus kampus akan direncanakan berdasarkan prosentase terbesar dari tempat yang sering didatangi oleh warga kampus. Hasil kuesioner dapat dilihat pada Gambar 11 dan Gambar 12.

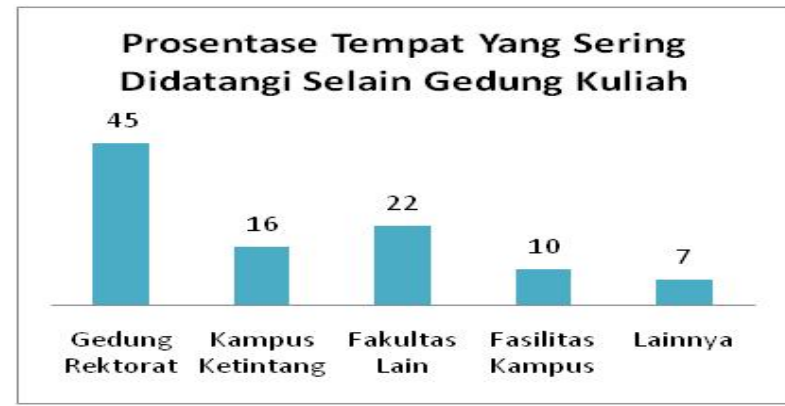

Gambar 11. Grafik Prosentase Tempat Yang Sering Didatangi Responden Mahasiswa.

\section{Prosentase Tempat Yang Sering Didatangi Selain Gedung Kuliah}

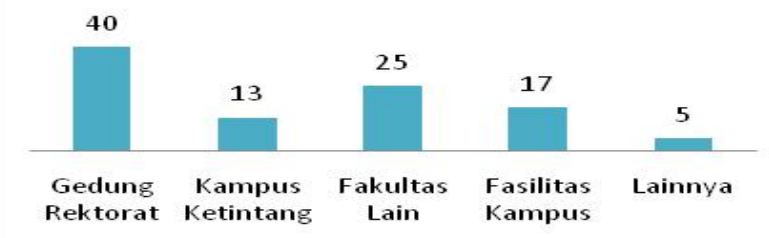


Gambar 12. Grafik Prosentase Tempat Yang

Sering Didatangi Responden Tendik

Berdasarkan Gambar 11 dan Gambar 12, dengan mengeliminasi tempat yang terletak di Kampus Ketintang, maka dapat direncanakan penempatan halte pada rute pembuka seperti yang ditunjukkan oleh Gambar 13.

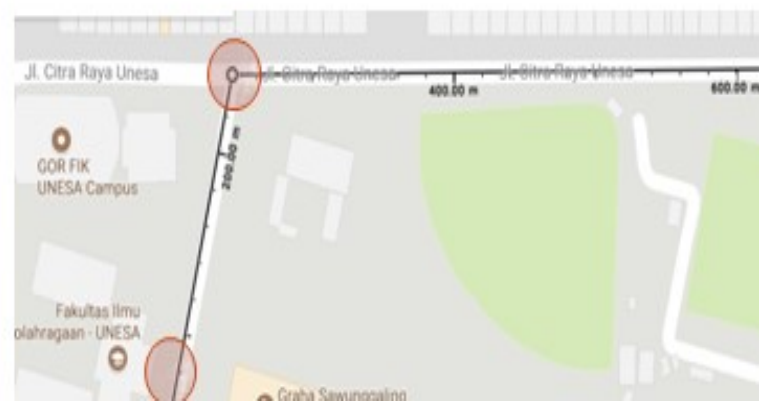

Gambar 13. Usulan Rencana Penempatan Halte Bus Kampus

Dalam merencanakan suatu sarana transportasi tentu perlu adanya atribut-atribut pelayanan yang diutamakan demi kenyamanana dari pengguna. Berdasarkan hasil kuesioner diketahui atribut pelayanan bus kampus berdasarkan persepsi responden dapat dilihat pada Gambar 14 dan Gambar 15.

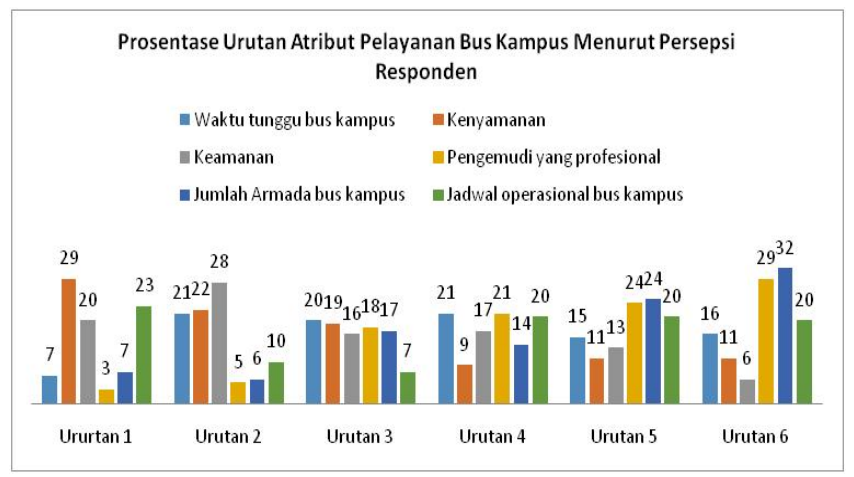

Gambar 14. Grafik Prosentase Urutan Atribut Pelayanan Bus Kampus Menurut Responden Mahasiswa.

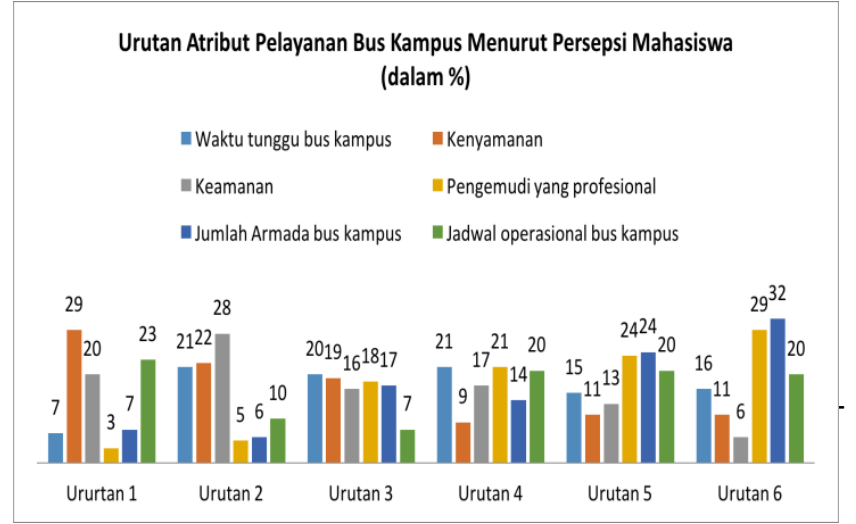

Gambar 15 Grafik Prosentase Urutan Atribut Pelayanan Bus Kampus Menurut Responden Tendik.

Berdasarkan Gambar 14 dan Gambar 15 diketahui atribut pelayanan yang menjadi prioritas menurut persepsi pengguna adalah keamanan, kenyamanan dan waktu tunggu.

\section{Kesimpulan dan Saran Kesimpulan}

1.

Responden

(mahasiswa dan tendik) sangat berminat terhadap rencana pengadaan bus kampus

2.

Sebagai permulaan, rute direncanakan intra kampus Lidah Wetan dengan pemberhentian di masingmasing Fakultas, rektorat, serta pintu masuk kampus (6 titik). Waktu operasional adalah pagi hari $(06.00-09.00)$ dan sore hari (15.00-18.00)

3.

Atribut pelayanan yang dipentingkan oleh responden adalah kenyamanan, keamanan, dan waktu tunggu

\section{Saran}

1. pengembangan prasarana yang lain seperti gedung parkir terpusat dan perbaikan sarana untuk pejalan kaki atau pesepeda

2.

Kebijakan eco campus perlu ditindaklanjuti dalam berbagai peraturan maupun SOP.

\section{DAFTAR PUSTAKA}

Ali, Muhammad. 1994. Analisis Teori Kasus dan Solusi. Yogyakarta: BPF.

Black, J.A. (1981) Urban Transport Planning: Theory and Practice, London,Cromm Helm.

Jayadinata, Johara T. (1999). Tata Guna Lahan Dalam Perncanaan Pedesaan Perkotaan dan Wilayah, Penerbit ITB, Bandung.

Miro Fidel. 1997. Sistem Transportasi Kota. Bandung: Penerbit Tarsito.

Singarimbun, M dan S. Effendi, (1989), Metode Penelitian Survai, -Rev. ed-, Lembaga Penelitian, Pendidikan dan Penerangan Ekonomi dan Sosial (LP3S), Jakarta. 
Tamin, O.Z. (2000)Perencanaan dan Pemodelan Transportasi, Edisi 2, PenerbitITB, Bandung.

Warpani, Suwardjoko. 1990. Merencanakan Sistem Perangkutan. Bandung:
Penerbit Instit

Zeithaml, V.A., Parasuraman, A. dan Berry, L.L., (1990), Delivering Quality Service, New York. 